\title{
Durchblick: Resilienzförderung
}

\section{„Von Innen nach Außen“ - Zu den Fotos von Jonathan Eckerle}

„Im Zuge meines im Oktober 2008 begonnenen Studiums der Sozialen Arbeit an der Alice-Salomon-Hochschule Berlin habe ich im Seminar „Analoge Fotografie“ eine sozialdokumentarische Portraitreihe angefertigt. Es ging darum, mit einer Spiegelreflexkamera verschiedene Aspekte des sozialen Raumes durch Fotografie darzustellen. Die Arbeit umfasst eine neun Bilder zählende Portraitreihe in schwarz/weiß von beeinträchtigten Jugendlichen.

Im Februar 2009 kehrte ich für eine Feldstudie an die EkkharthofSchule für seelenpflegebedürftige Kinder und Jugendliche an den Bodensee in die Schweiz zurück. An dieser anthroposophischen Einrichtung habe ich von 2006 bis 2008 als Klassenbegleiter für geistig und körperlich Beeinträchtigte gearbeitet. Die tägliche Willenskraft zum Lernen und Leben der Jugendlichen hat immer meinen größten Respekt erfahren und so wollte ich dieses Projekt mit ihnen gemeinsam realisieren. Meine lehrreichen und einzigartigen Erfahrungen als Klassenbegleiter wollte ich mit einem dokumentarisch-künstlerischen Ansatz zum Ausdruck bringen. Alle Aufnahmen entstanden in einer sonnigen Februarwoche, gegenüber dem schuleigenen Biotop, mal mit und mal ohne Schneedecke.

Sehr zeitaufwändig an diesem Projekt war die Laborarbeit in der hochschuleigenen Dunkelkammer. Hier wählte ich mithilfe eines Vergrößerungsgerätes den letztendlichen Bildausschnitt und entwickelte diesen in den drei Chemikalienbädern. Die hierfür notwendigen Negative lieferte mir meine Canon EOS $3000 \mathrm{~V}$, bestückt mit einem Ilford XP2 Film (ISO 400).“

\section{JONATHAN ECKERLE}

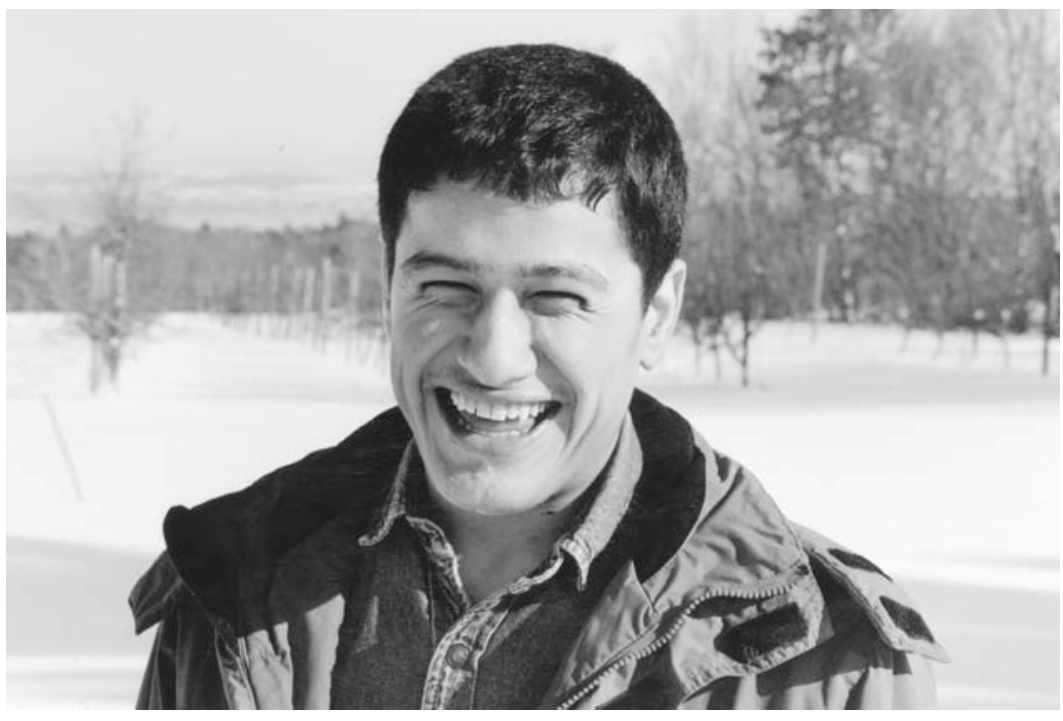

R. (15) IST KURDISCHER IRAKER, ER HAT IM KRIEG EIN BEIN VERLOREN UND KAM MIT SECHS JAHREN IN DIE SCHWEIZ. ALLE FOTOS: JONATHAN ECKERLE

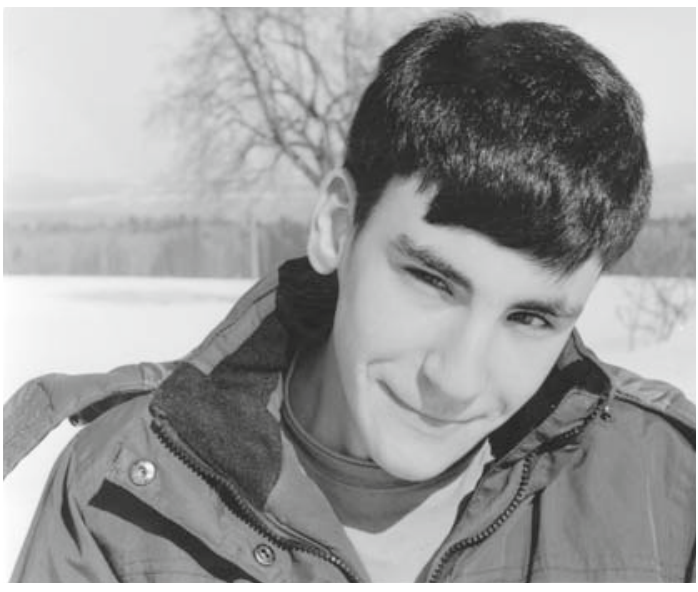

KADIR (15) LEBT MIT SEINER FAMILIE IN KREUZLINGEN UND STAMMT URSPRÜNGLICH AUS DER TÜRKEI.

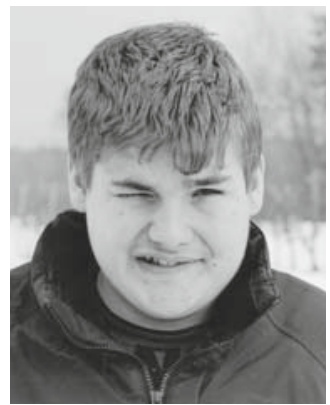

ZUM TITELBILD:

RAMON (17) LEBT MIT SEINER FAMILIE IN NEUWILEN UND KOMMT TÄGLICH MIT DEM SCHULBUS AN DEN EKKHARTHOF.

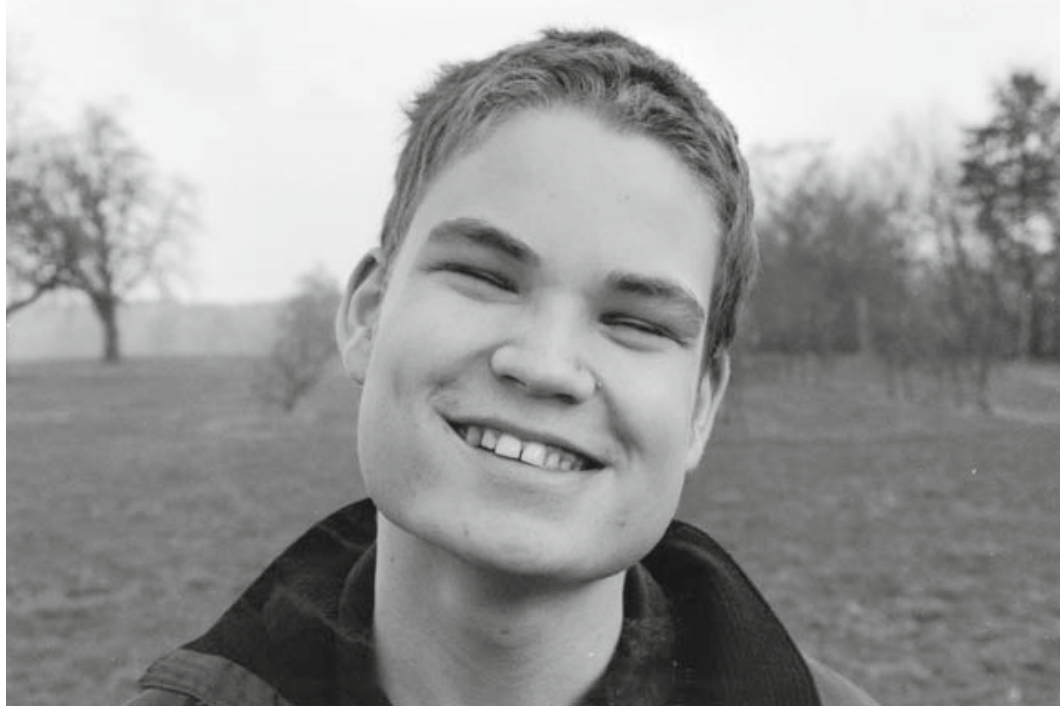

PATRICK (17) IST SCHWEIZER UND LEBT AUF DER WOHNGRUPPE PEGASUS. 